Leading article

\title{
Laparoscopic surgery for gastro-oesophageal reflux disease
}

Much has changed since this Journal last published in 1992 a leading article on the surgical treatment of gastrooesophageal reflux disease (GORD). ${ }^{1}$ The introduction of laparoscopic anti-reflux surgery has led to renewed interest in the operative treatment of GORD. Anti-reflux surgery had fallen out of favour with physicians throughout the 1980 s as better medical therapies, notably proton pump inhibitors, became available, thus avoiding the morbidity and occasional mortality inherent in surgical treatment. Although in specialist centres anti-reflux surgery could give long-lasting symptom relief in $90 \%$ of patients over 10 years, ${ }^{2}$ which was at least as good as the best medical therapy available at the time, ${ }^{3}$ many physicians felt that the side effects of surgery were frequent and the long term results less impressive outside such centres. Laparoscopic anti-reflux surgery, identical with that previously performed via a laparotomy, was introduced in $1991 .{ }^{4}$ Early reports indicated that the operative morbidity and hospital stay were much reduced owing to the avoidance of a painful abdominal incision. Technical aspects of a number of effective anti-reflux barriers based on different types of fundoplication have now been mastered in many centres, ${ }^{56}$ and the time has come for a proper appraisal of the indications for surgery, pre- and postoperative assessments and the choice of operation for treating GORD.

Three groups of patients can be identified who are particularly suited to laparoscopic anti-reflux surgery. Numerically the most important of these are patients who have refractory disease on medical therapy. A variety of factors are involved. Around $10 \%$ of patients with GORD are acid hypersecretors who may need large doses of acid suppressive therapies to eradicate their symptoms. ${ }^{7}$ Patients taking concomitant medications which promote reflux may also require large doses of acid suppressive drugs, and certainly the results of one study in patients with erosive oesophagitis indicated that in the long term, maintenance therapy comprising $20 \mathrm{mg}$ omeprazole daily is far from perfect because $47 \%$ of patients developed recurrent endoscopic oesophagitis over a five year follow up period. ${ }^{8}$ One group of patients with refractory GORD who merit special consideration are those with underlying disorders of oesophageal body motor function such as scleroderma or severe reflux symptoms following pneumatic dilatation for achalasia. There are no clear data to indicate the best form of treatment for such patients although few would argue with the notion that aggressive medical therapy should be tried in the first instance. ${ }^{9}$ These patients require very careful assessment if anti-reflux surgery is to be contemplated.

A second, readily identifiable group of patients are those who are often described as "volume refluxers". They are bothered by persistent fluid regurgitation despite adequate control of their heartburn with acid suppressive drugs. These patients characteristically are young and have negligible lower oesophageal sphincter pressures. They often experience nocturnal symptoms when they are recumbent and in extreme cases develop pulmonary symptoms, possibly as a result of aspiration. Attacks of wheezing, coughing, choking, as well as bringing back fluid into the mouth are all symptoms associated with this type of gross reflux..$^{10}$ It can be sufficiently severe to cause dental erosions.

The final patient group are those individuals who develop oesophageal strictures and are thought to have many years of life expectancy and who require dilatation more than a few times each year despite taking proton pump inhibitors. It seems both illogical and uneconomical to embark on a long term programme of dilatations without at least assessing the suitability of such individuals for laparoscopic anti-reflux surgery.

In addition to the above groups, there are two other patient populations where the role of laparoscopic surgery is more controversial. Some patients simply do not wish to take tablets for the rest of their lives. There are no long term studies which have prospectively compared optimal medical therapy (presumably including a proton pump inhibitor) with laparoscopic anti-reflux surgery. The long term effects of proton pump inhibitors taken for 10 years or more remain unknown and we understand very little about the consequences of inadequate medical therapy over a long period of time. It is important, however, to separate such a group of patients from those who are noncompliers with medical therapy who have an unrealistic approach to the overall management of their condition, and who demonstrate an unwillingness to adopt any of the proven lifestyle measures which will minimise their symptoms in addition to showing poor compliance with powerful anti-secretory drugs.

The other important issue relates to the role of antireflux surgery in patients with Barrett's oesophagus. There are no data to indicate that optimal medical therapy - that is, inhibition of gastric acid production with a proton pump inhibitor, will prevent the development of Barrett's oesophagus, or in those who have the condition, the change from metaplasia to dysplasia. Despite occasional reports to the contrary, there are no convincing data that a successful anti-reflux operation can also prevent this progression. ${ }^{11-13}$ There is at least with anti-reflux surgery a potential advantage, that by not only minimising acid reflux there is also prevention of the reflux of duodenal contents which has been implicated in the pathogenesis of Barrett's metaplasia. ${ }^{1-16}$ If further experimental studies continue to support the hypothesis that the non-acid components of the refluxate are important in the development of Barrett's oesophagus and in the progression to dysplasia, then it is likely that a stronger case could be made for the role of anti-reflux surgery in such patients. At the moment, however, such a recommendation is premature.

If the low morbidity achieved in the best series means that the pendulum has swung back to surgery, then it is important that the right operation is done for the right 
patient. Every patient must at least have endoscopic or histologically proven oesophagitis in order to substantiate a diagnosis of GORD as opposed to gastro-oesophageal reflux symptoms. Preferably, 24 hour $\mathrm{pH}$ monitoring with manometric placement of the $\mathrm{pH}$ catheter should be performed, particularly in symptomatic patients with no endoscopic oesophagitis. Manometry is used not only for this accurate $\mathrm{pH}$ catheter placement but also to assess oesophageal body motor function and to measure lower oesophageal sphincter pressure. Although there is no evidence that manometry can be used to predict the outcome of anti-reflux surgery, this does not mean that the test is of no value. ${ }^{17}$ Over $80 \%$ of patients with endoscopic oesophagitis will have a demonstrable sphincter defect on laboratory based manometry and in virtually all other patients, reflux associated with transient lower oesophageal sphincter relaxations can be demonstrated either by ambulatory manometry or a specialised catheter which can reliably record sphincter relaxations. The risk of postoperative dysphagia following an anti-reflux procedure is much higher in patients with absent or severely disordered oesophageal peristalsis, and particular consideration should be given to this finding before offering such patients anti-reflux surgery.

All operations for reflux aim to abolish heartburn and regurgitation without producing dysphagia or the inability to belch postoperatively. As in the open era there are wide variations in the procedures adopted but all share a common feature - that is, a wrap of the gastric fundus around the lower oesophagus to recreate a lower oesophageal high pressure zone. Most centres have adopted the short floppy Nissen fundoplication with a $360^{\circ}$ wrap as the operation of choice for patients with normal oesophageal body motility because previously this operation was shown to produce excellent results in $90 \%$ of patients over the longest follow up of some 10 years. ${ }^{2}$ Good results have been reported in several centres with anterior or posterior incomplete wraps but with shorter follow up periods. ${ }^{18} 19$ Few randomised controlled trials of full or partial wraps have been performed, but it is clear that at least up to five years, both procedures effectively control reflux in the vast majority of patients.

All fundoplications consist of a wrap around the lower oesophagus so that at least $1 \mathrm{~cm}$ of distal oesophagus is subjected to La Place's Law, where pressure is proportional to wall tension and inversely proportional to the radius. An effective fundoplication is associated with a substantial reduction in the rate of transient lower oesophageal sphincter relaxations as well as a reduction in the proportion of relaxations accompanied by reflux. ${ }^{20}$ In patients with adequate oesophageal body motor function, the floppy Nissen with a $360^{\circ}$ wrap, or one of its modifications such as the Rosetti procedure, is appropriate. Patients should be counselled about dysphagia in the early postoperative period and of some reduction in their meal capacity with early satiety. Dysphagia rarely persists beyond six weeks and the risk of this complication can be minimised by making the wrap no more than $2 \mathrm{~cm}$ long and using an oesophageal bougie of at least 50 French diameter. $^{2}$ There is some debate about whether dysphagia is influenced by division of the short gastric vessels. While it is indisputable that proper mobilisation of the posterior aspect of the fundus is essential to enable the wrap to be brought behind the oesophagus without difficulty, a recent randomised trial of Nissen fundoplication with and without division of the short gastric vessels found no difference in early postoperative dysphagia (presented at the Association of Endoscopic Surgeons of Great Britain and Ireland, 1995). It should also be borne in mind that in the Rosetti modification of the Nissen technique where the short gastric vessels are not divided, postoperative dysphagia rates are no different from standard fundoplication with short gastric division. Failure to achieve an adequate crural repair behind the wrap is associated with a risk of early postoperative para-oesophageal herniation and proximal wrap migration and it is accepted that posterior crural repair should be performed. ${ }^{21}$ A $360^{\circ}$ wrap should probably be avoided in patients with inadequate oesophageal peristalsis. Although there are no controlled or even comparative trials to support this view, the argument in favour of this approach is logical based on current knowledge of the pathophysiology of reflux disease and an understanding of how these operations work. ${ }^{22}$ Both the Toupet and Watson techniques ${ }^{18}{ }^{19}$ are associated with very low rates of dysphagia and an absence of gas bloat, and a number of centres have advocated an approach to tailoring the anti-reflux procedure to the results of detailed investigations. Early results from such centres indicate that an excellent clinical result and absence of reflux on 24 hour $\mathrm{pH}$ monitoring can be achieved in over $90 \%$ of patients. ${ }^{22}$

The correlation between postoperative reflux symptoms and 24 hour $\mathrm{pH}$ monitoring is poor ${ }^{21}$ and it is imperative that an objective measure of recurrent or persistent reflux disease is obtained in symptomatic postoperative patients.

Assessment of the postoperative result should ideally be by an independent observer and should consider not only traditional outcome measures but also the impact of surgery on the quality of the patient's life. There is a real need for properly constructed prospective clinical trials to compare laparoscopic anti-reflux surgery with medical therapy.

Now that many surgeons are becoming skilled at laparoscopy, we should question the widespread adoption of anti-reflux surgery by generalists without a special interest in reflux disease. Published series in the open and laparoscopic eras have shown that anti-reflux surgery can be accomplished with excellent long term results in the hands of interested and dedicated surgeons. If laparoscopic anti-reflux surgery is to become an established part of the treatment of GORD, then it must be performed with the same careful attention to detail as its open counterpart. It is vitally important that surgeons performing anti-reflux surgery should have access to high quality investigative facilities. Hospitals offering this type of surgery require not only endoscopic facilities but also oesophageal manometry and $\mathrm{pH}$ monitoring. Only by careful attention to the details of investigation, allied to the development of a high degree of technical proficiency with the surgery itself and careful independent postoperative assessments, can surgeons expect to produce excellent results with low morbidity and negligible mortality.

D ALDERSON

University Department of Surgery, C R B WELBOURN

Bristol Royal Infirmary,

Marlborough Street,

Bristol BS2 $8 H W$

1 Dehn TCB. Surgery for uncomplicated gastro-oesophageal reflux. Gut 1992; 33: 293-4.

2 DeMeester TR, Bonavina L, Albertucci M. Nissen fundoplication for gastro-esophageal reflux disease. Evaluation of primary repair in 100 gastro-esophageal reflux disease. Evaluation of
consecutive patients. Ann Surg 1986; 204: 9-20.

3 Spechler SJ. Comparison of medical and surgical therapy for complicated gastro-esophageal reflux disease in veterans. $N$ Engl f Med 1992; 326: gastro-eso

4 Dallemagne B, Weerts JM, Jehees S. Laparoscopic Nissen fundoplication: Preliminary report. Surg Laparosc Endosc 1991; 1: 138-40.

5 Cuschieri A, Hunter J, Wolfe B, Swanstram LL, Hutson W. Multi-centre prospective evaluation of laparoscopic anti-reflux surgery: Preliminary report. Surg Endosc 1993; 7: 505-10.

6 Hinder RA, Filipi CJ, Wetscher G, Neary P, DeMeester TR, Perdikis G. Laparoscopic Nissen fundoplication is an effective treatment for gastroesophageal reflux disease. Ann Surg 1994; 220: 472-83.

7 Barlow AP, DeMeester TR, Ball CS, Eypasch EP. The significance of the gastric secretory state in gastro-esophageal reflux disease. Arch Surg 1989; 124: 937-40. 
8 Klinkenberg-Knol EC, Festen HPM, Jansen JBMJ, Lamers CBHW, Nelis $\mathrm{F}$, Snel $\mathrm{P}$, et al. Long-term treatment with omeprazole for refractory reflux esophagitis: efficacy and safety. Ann Intern Med 1994; 121: 161-7.

9 Shoenut JP, Wieler JA, Micflikier AB. The extent and pattern of gastroesophageal reflux in patients with scleroderma oesophagus: The effect of low dose omeprazole. Aliment Pharmacol Ther 1993; 7: 509-13.

10 Rooth M, Bake B, Sandberg N, Olbe L, Lundell L. Pulmonary function and gastro-esophageal reflux disease - Effect of reflux controlled by and gastro-esophageal reflux disease - Effect

11 McCallum TW, Polepalle S, Davenport K, Frierson H, Boyd S. Role of antireflux surgery against dysplasia in Barrett's oesophagus [abstract]. Gastroenterology 1991; 100: A121.

12 Sagar PM, Ackroyd R, Hosie KB, Patterson JE, Stoddard CJ, Kingsnorth AN. Regression and progression of Barrett's oesophagus after anti-reflux surgery. Br $\mathcal{F}$ Surg 1995; 82: 806-10.

13 Gore S, Healey CJ, Sutton R, Eyre-Brook IA, Gear MWL, Shepherd NA, et al. Regression of columnar lined (Barrett's) oesophagus with continuous omeprazole therapy. Aliment Pharmacol Ther 1993; 7: 623-38.

14 Kauer WKH, Peters JH, DeMeester TR, Ireland AP, Bremner CG, Hagen JA. Mixed reflux of gastric and duodenal juices is more harmful to the esophagus than gastric juice alone. The need for surgical therapy is reemphasised. Ann Surg 1995; 222: 525-33.
15 Caldwell MTP, Lawlor P, Byrne PJ, Walsh TN, Hennessy TPJ. Ambulatory oesophageal bile reflux monitoring in Barrett's oesophagus. $\mathrm{Br} 7 \mathrm{Surg}$ 1995; 82: 657-60.

16 Vaezi MF, Richter JE. Synergism of acid and duodeno-gastro-oesophageal reflux in complicated Barrett's oesophagus. Surgery 1995; 117: 699-704.

17 Mughal MM, Bancewicz J, Marples $\mathrm{M}$. Oesophageal manometry and $\mathrm{pH}$ recording does not predict the bad results of Nissen fundoplication. $\mathrm{Br}$ recording does not pred.

18 Lundell L, Abrahamsson H, Ruth M, Rydberg L, Lönroth H, Olbe L. Longterm results of a prospective randomised comparison of total fundic wrap (Nissen-Rossetti) or semifundoplication (Toupet) for gastro-oesophageal reflux. Brf Surg 1996; 83: 830-5.

19 Watson A, Spychal RT, Brown MG, Peck N, Callander N. Laparoscopic physiological anti-reflux procedure: Preliminary results of a prospective, symptomatic and objective study. Br f Surg 1995; 82: 651-6.

20 Ireland AC, Holloway RH, Toouli J, Dent J. Mechanisms underlying the anti-reflux action of fundoplication. Gut 1993; 34: 303-8.

21 Gotley DC, Smithers BM, Rhodes M, Menzies B, Branicki FJ, Nathanson L. Laparoscopic Nissen fundoplication - Two hundred consecutive cases. Gut 1996; 38: 487-91.

22 Fuchs KH, Heimbucher J, Freys SM, Thiede A. Tailored concept of antireflux operations. Dis Oesophagus 1994; 7: 250-4. 